\title{
Research on the Application of Ceramic Art Symbol in Visual Image Design of Large - scale Sports
}

\author{
Cunjun Xie and Leilei Tian \\ ${ }^{1}$ Jingdezhen College, Jingdezhen, Jiangxi 333000; \\ ${ }^{2}$ Jingdezhen Ceramic University, Jingdezhen, Jiangxi 333403
}

\begin{abstract}
Jingdezhen becomes the world culture in the bright wonderful work because of its ceramic art with its profound cultural heritage and specific forms of expression. Ceramic art not only retains the Chinese nation's extraordinary cultural heritage, but also "meaningful form" shows the pulse of the times, revealing the splendor of the Chinese culture. Provincial Sports Games will be held in Jingdezhen in 2018, the Sports Game of Jiangxi Province is the province's large-scale comprehensive sports event held every four years. This topic aims to use the ceramic art symbol, to create a unique provincial sports visual image, making the 2018 Jingdezhen Provincial Games become a unique, cultural heritage, a connotation of the provincial Games, and take this opportunity to further start the world Porcelain Jingdezhen city brand, realizing the pottery symbols is used in the provincial sports event visual image design, and strive to make the 2018 Provincial Sports Games become a classic.
\end{abstract}

Keywords: Ceramic art symbol; Sporting event; Visual image design; Jiangxi provincial games

\section{陶瓷艺术符号在大型体育赛事视觉形象设计中的 应用研究}

谢存军田蕾蕾

( 景德镇学院体育系, 江西景德镇 333000; 景德镇陶瓷大学, 江西景德镇 333403 )

摘要: 景德镇的陶瓷艺术以其精深的文化底蕴和特定的表现形式, 成为世界文化中璀嗓的奇薢。陶瓷艺术既蕴藏养中华 民族卓绝超凡的文化传承, 又以 “有意味的形式” 彰显着时代的脉搏, 透射出中华文化的神华异彩。2018 年省运会在景德 镇举办, 江西省运动会是每四年举办一次的全省大型综合性体育盛会。本课题旨在运用陶瓷艺术符号, 塑造独特的省运会视 觉形象, 将 2018 年景德镇省运会举办成为有特色、有文化底蕴、有内涵的一届省运会, 并且借此机会进一步打响世界瓷都 景德镇的城市品牌, 将陶艺符号运用在省运会赛事视觉形象设计中, 力争使 2018 年省运会成为历史经典。

关键词: 陶瓷艺术符号; 体育赛事; 视觉形象设计; 江西省运会

中图分类号: G807 文摘标识码: A

\section{1 前言}

“陶瓷文化走出去作为中华文化走出去的重要组成部分, 对于景德镇来说是个难得的机会, 同时更是 义不容辞的责任。” 中国传统陶瓷艺术有一套系统规范的符号体系, 从造型、釉色、装饰、题材、风格等 都可以用符号进行表达, 其中尤其以传统陶瓷的吉祥纹饰具有明显的符号和象征意义。通过符号很容易让 人看到其民族、地域、时代、文化特征, 也与传统文化的精神完全一致。景德镇要借省运会契机充分发挥 陶瓷文化走出去的重要作用, 凸显世界瓷都的品牌价值, 加深世界对中华文化的理解和认同, 为推动中华 文化走出去贡献 “景德镇力量”。 


\section{2 研究方法}

\section{1 文献资料法}

收集并使用权威性较高的文献资料, 包括符号学、陶艺符号、体育赛事、视觉形象设计等的专著、各 类学术论文、实物照片和图片、报纸期刊杂志、研讨会资料、网络资源, 通过对大量的文献进行整理、综 述、初步分析，探寻课题研究的事实基础、理论支撑、方法和思想启迪。

\section{2 考察法}

对中国大型体育赛事如， 2008 年第二十九届北京奥运会、2010 第十六届广州亚运会、2013 年第十二 届辽宁全运会、2014 年第十四届江西省运会等国内多级别大型体育赛事的视觉形象等进行考察和调研, 获 取更多的第一手资料, 考察 2018 年第十五届景德镇省运会场馆、项目等赛事元素, 为研究开展提供完整 的事实和依据。

\section{3 专家访谈法}

根据研究需要, 对有关陶瓷艺术相关专家、体育赛事相关专家等进行专门访谈和咨询, 寻求更多专家 支持, 探讨和请教相关问题, 为本研究提供相关信息和拓展解决问题的思路, 解决研究中的重、难点问题。

\section{4 归纳演绎法}

将文献研究、实地调研和考察、专家访谈等获得的各类资料、事实、信息统一进行归纳、分析和演绎, 对省运会赛事视觉形象进行构思及设计，使其融入陶艺符号。

\section{5 逻辑分析法}

对所收集到的资料采用了归纳、类比、综合分析等方法进行分析与研究。对陶艺符号、大型体育赛事 视觉形象设计进行归类整理, 与景德镇本地实际情况进行实际密切结合, 结合发展规律大胆创新设计。

\section{3 概念释义}

\section{1 陶瓷艺术符号释义}

陶瓷艺术, 既包括狭义上的陶器艺术, 也包括瓷艺。中国传统陶瓷艺术有一套系统规范的符号体系, 从造型、釉色、装饰、题材、风格等可以用符号进行表达, 其中尤其以传统陶瓷的迹象纹饰具有明显的符 号和象征意义 ${ }^{1}$ 。陶瓷艺术符号学是用符号学原理来解读各种陶艺符号意义以及探讨陶艺语高的学问, 其 基本任务在于探讨陶艺语高的结构、陶艺木文的意义构成、陶艺语高与陶艺木文之间的关系，以及陶艺符 号发生功能的条件。陶瓷艺术符号, 是国内大型体育赛事视觉形象设计中的中国特色元素, 是中国传统文 化和璀璨艺术的表现形式之一。

\section{2 大型体育赛事释义}

大型体育赛事一般指国际的或者国内的, 各种大型的、综合性的或者单项的运动竞赛。大型体育赛事 的特点是：级别高、规模大、投资多、主办单位的权威性强。

\section{4 陶瓷艺术符号在 08 年奥运会中的应用}

\section{1 青花瓷艺术符号在 08 年奥运会中的应用}

青花瓷，是景德镇四大名瓷之一，是中国陶瓷艺术的主流品种之一，历经唐、宋、元、明、清几代的 发展, 日益完善。“素胚勾勒出青花笔锋浓转淡, 瓶身描绘的牡丹一如你初妆”, 2008 年, 奥运会在北京 
举办, 一组参照青花瓷图案风格设计的礼仪小姐旗袍, 白底蓝花, 亮相会场。秀美的中国姑娘穿上它, 亭 亭玉立，带给世界以清新典雅、高贵大方的感受，代表中国的传统文化展现给世界。

\section{2 “薄如纸” 北京 2008 年奥运会特制陶瓷纪念电话卡}

《北京 2008 奥韵瓷质纪念电话卡》由北京奥组委授权批准、中国瓷都景德镇精工制作、中国网通荣 誉出品。瓷制电话卡传承了景德镇传统制瓷工艺的精髓, 这套艺术品的研制是以明代吴昊十九 “垩公窑” 利制薄胎瓷的工艺为基础, 创造出小型平板成型技法, 每片电话卡厚度仅有 $0.25 \mathrm{~cm}$, 真正做到轻薄如纸, 电 话卡正面采用宋代著名影青釉施色, 缜芗如玉, 背面瓷壁不施釉但光洁性能好, 正体现出所选用的瓷泥之精 细, 泥性之纯洁。

\section{3 “白如玉” 的环保型奥运瓷}

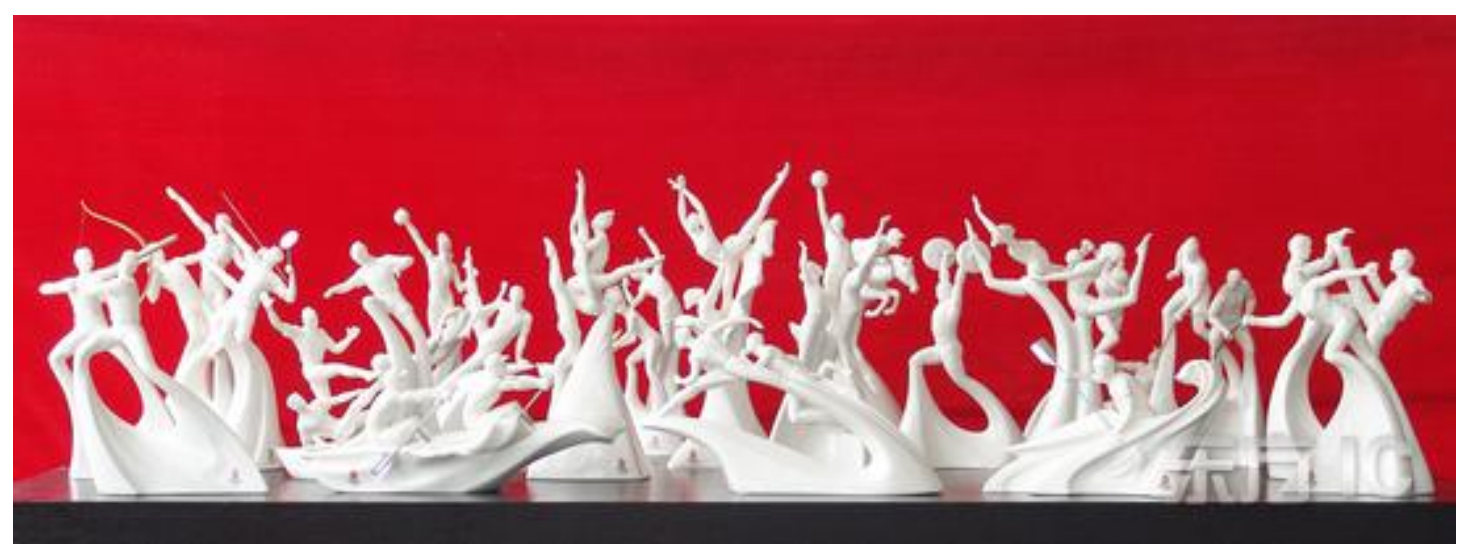

图 1 运动项目陶瓷摆件

2008 年奥运会开幕之前，一套名为 “运动项目陶瓷摆件”（如图 1 所示）的环保型奥运特许瓷，在江 西省景德镇亮相。该作品保持环保不加骨粉, 以技术达到与骨质瓷的通透效果。这得益于景德镇雄厚的奥 运陶瓷艺术文化底蕴和高超的制瓷工艺。2008 北京奥运会的召开, 是百年不遇的盛世, 这 29 款奥运运动 项目陶瓷摆件记录了这段辉煌的历史, 有着特殊的历史意义和传承使命。使用陶瓷的表现形式将奥运项目 的经典动作刻画出来, 这在全球还是首次。这套收藏品将西方新艺术流畅线条和东方典雅的人文气质相融 合, 将大自然的华美风采立体呈现于瓷品之上, 充分表现出运动员之律动与美感, 将奥运赛场瞬间之美定 格为永恒之美，并将奥运精神长驻于瓷品之上。

\section{4 “明如镜” 的青花瓷地铁奥运支线}

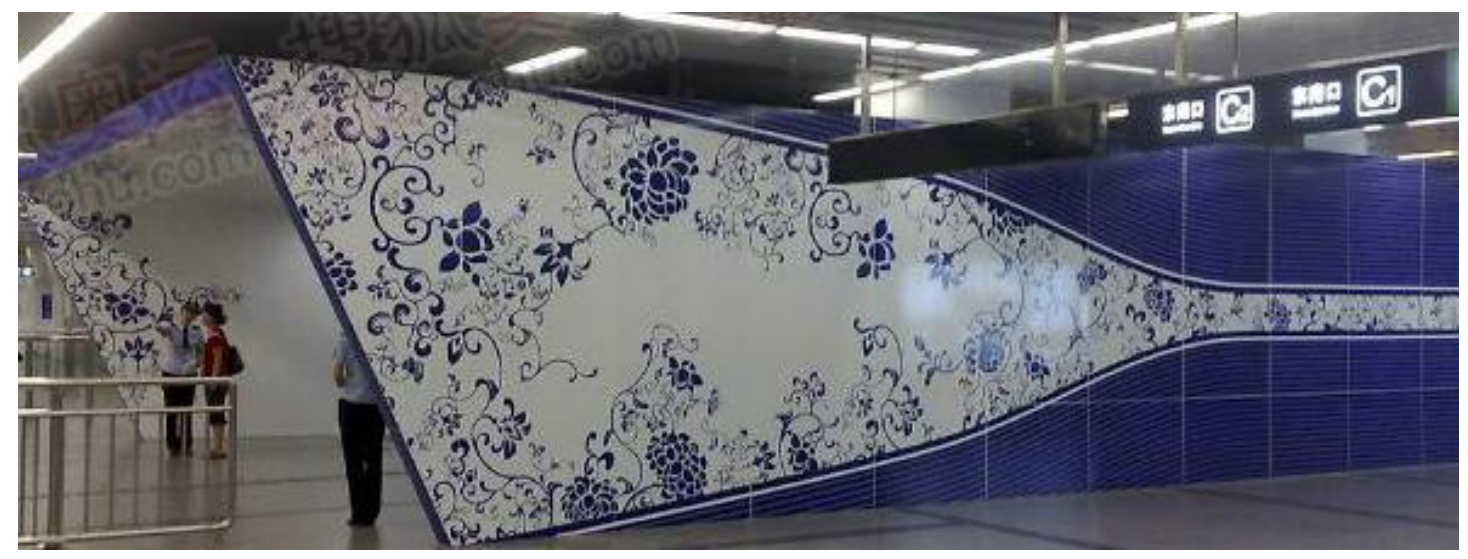

图 2 中国元素一一青花瓷装饰下的地铁 
图 2 所示, 奥运期间, 北京地铁五号, 十号线的墙面装饰和立柱的纹饰, 通过这些人们日常所见的建 筑装饰, 采用青花瓷花纹纹路, 梅花、兰花、中国结、龙、古人赛龙舟图案, 充分运用了青花瓷艺术符号, 展现给世人古典、高雅、精致的建筑艺术享受。

\section{5 景德镇 2018 江西省运会视觉形象设计思路}

\section{1 陶艺符号在省运会视觉形象设计中的应用研究}

整理大型体育赛事如奥运会、全运会、各省省运会及历届江西省运会视觉形象设计的特点、文化内 涵及其发展规律, 在遵循发展规律的前提下, 锐意创新, 将陶艺符号应用到省运会赛事视觉形象设计中来。 从造型符号、色彩符号、图形纹饰符号、工艺装饰符号等角度出发对省运会宣传片、开幕式表演、会徽、 吉祥物、火炬、体育项目图标及大会视觉识别系统等省运会视觉形象进行构思和设计。

例如图 1 所示, 火炬分为上下两个部分, 上半部分是由景德镇具有百年历史的 “太平窑, 盼太平之意” 的太平窑为原型, 下半部分则由具有景德镇特色的现代感十足的青花玲珑为主要题材, 展现了景德镇鲜明 的历史传统文化。

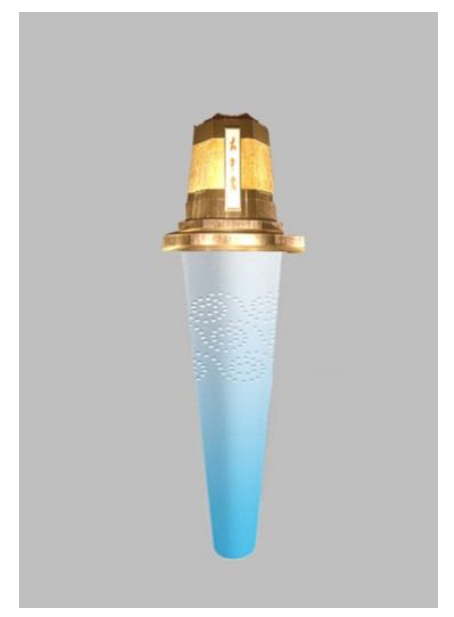

图 3 太平火炬设计思路之一

\section{2 陶艺符号在省运会景观系统设计中的应用}

大型体育赛事的景观一般包括两个部分，一是赛事场馆景观; 二是赛事城市景观。使用陶艺符号增强 2018 年省运会的个性形象, 烘托省运会气氛和现场观众的竞技氛围, 营造景德镇这座城市的整体盛会气氛。 赛事景观的物质性要素有挂旗、围栏织物、路障覆盖物、计时计分牌、赛事人员制服、地面图形、颁奖台、 新闻背景板等。在以上赛事景观要素的设计中应用陶艺符号, 是本次省运会突出景德镇特色的重要手段。

例如图 2 所示, 颁奖礼仪小姐的礼服设计思路, 可以先从景德镇陶瓷大学礼仪队的师生们设计成功的 “四大名瓷” 陶瓷服饰中获得思路和设计启发, 江西省运会的颁奖仪式上, 设计 “青花” “粉彩” “颜色釉” “玲珑” 为主题的四款颁奖礼仪服装。分别按照颁奖志愿者、嘉宾引导员、运动员引导员和托盘员的不同 职能设计了不同款式。这四个系列的礼服将分别出现在不同的场馆及比赛中。 


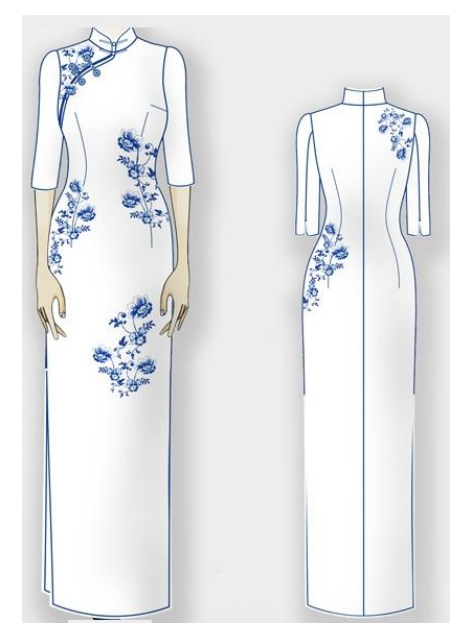

图 4 颁奖礼仪小姐的青花礼服设计思路之一

\section{6 结论}

从造型符号、色彩符号、图形纹饰符号、工艺装饰符号等角度出发对省运会会徽、吉祥物、火炬、体 育项目图标及大会视觉识别系统等省运会视觉形象进行构思和设计。既要充分展现景德镇陶瓷艺术文化, 举办有景德镇特色、有陶瓷文化内涵、有陶瓷艺术特色的一届省运会, 又要将我省最重要的体育赛事与陶 瓷艺术有机结合, 水乳交融; 既要学习 2008 年 “中国特色” 北京奥运会的成功办赛经验, 又要秉承节俭 办赛的原则。做到既突出景德镇陶瓷艺术特色, 又要还原江西省运动会本色。力争使 2018 年江西省运会 视觉形象设计独树一帜。

将陶艺符号应用到 18 年省运会视觉形象设计中来, 助力 18 年省运会为全省乃至全国人民瞩目, 力争 突破历史创造佳绩; 借省运会在景德镇举办的契机, 在全国乃至世界范围内宣传陶瓷文化, 提升景德镇品 牌, 通过省运会视觉形象体系中陶艺符号所展现出的景德镇文化与陶瓷艺术特色, 让世界了解瓷都、认识 瓷都。

江西省运会, 经历了六十多年的发展, 作为全省大型综合性体育盛会, 旨在推动全省各地体育事业的 发展, 发现培养优秀体育后备人才。本课题以 2018 年江西省运会视觉形象为设计样板, 从陶瓷艺术符号 出发, 合理构思, 大胆设计, 望对省运会赛事视觉形象设计的理论提出有价值的参考及建议。

\section{致谢}

基金项目:景德镇市社会科学联合会基金项目《陶瓷艺术符号在大型体育赛事视觉形象设 计中的应用研究》(2016-021)

\section{Acknowledgement}

Fund project: Jingdezhen City Social Science Foundation Fund Project "The application ceramic art symbol in visual image design of large-scale sports event" (2016-021)

\section{参考文献}

[1]罗兰・巴特. 符号学原理 [M]. 北京: 三联书店出版社, 1999.

[2] 肖绚, 陈致敏. 论陶艺创作中的符号学 $[J]$, 中国陶瓷, 2005, 41 (5): 32-34.

[3] 王军. 奥林匹克视觉形象的历史研究 [M]. 北京: 北京体育大学出版社, 2004:4-8.

[4]王琨. 奥运会会标图形设计研究[D]. 南宁: 广西师范大学, 2012. 
[5]孟幻, 冯刚. 谈当代艺术设计对传统文化的借鉴 $[J]$. 东华大学学报 (社会科学版), 2009, 9 (4): 314-317.

$[6]$ 聂阳. 大型体育赛事视觉形象设计研究 $[J]$. 美术大观

[7]张浩. 从奥运会标志发展历程探索标志设计的时代性 [D]. 南京: 西安美术学院, 2007. 36-36.

[8]张力丽. 现代奥运会徽设计的世界性与本土化 [D]. 南京: 苏州大学，2006.21-24.

作者简介:

谢存军 (1978.8一), 男, 景德镇学院讲师, 硕士, 研究方向: 体育艺术与审美

田蕾蕾 (1982.5一), 女, 景德镇陶瓷大学讲师, 硕士, 研究方向: 数字体育

\section{References}

[1] Roland Bart. Semiotics Principles [M]. Beijing: Sanlian Bookstore Publishing House, 1999.

[2] Xiao Xuan, Chen Zhimin. Discussion on the symbol of pottery creation [J], China Ceramics, 2005, 41 (5): 32-34.

[3] Wang Jun. Study on history of Olympic visual image [M]. Beijing: Beijing Sports University Press, 2004: 4-8.

[4] Wang Kun. Olympic Games logo graphics design research [D]. Nanning: Guangxi Normal University, 2012.

[5] Meng Huan, Feng Gang. Comments on the reference of contemporary art design to traditional culture [J]. Journal of Donghua University (Social Science Edition), 2009, 9 (4): 314-317

[6] Nie Yang. Study on visual image design of large-scale sports events [J]. Fine Art.

[7] Zhang Hao. From the development of the Olympic logo to explore the times of the logo design [D]. Nanjing: Xi'an Academy of Fine Arts, 2007, 36-36.

[8] Zhang Lili. The world and localization of modern Olympic emblem design [D]. Nanjing: Suzhou University, 2006, 21-24. 